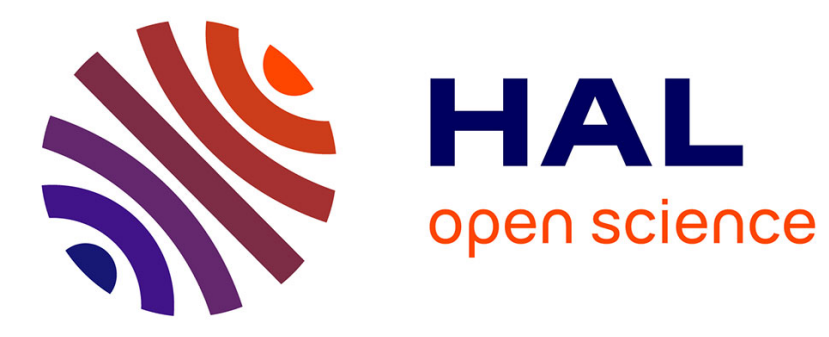

\title{
Unidentified deceased persons
}

Roberto C. Parra, Élisabeth Anstett, Pierre Perich, Jane E. Buikstra

\section{To cite this version:}

Roberto C. Parra, Élisabeth Anstett, Pierre Perich, Jane E. Buikstra. Unidentified deceased persons: Social life, social death and humanitarian action. Roberto C. Parra; Sara C. Zapico; Douglas H. Ubelaker. Forensic Science and Humanitarian Action: Interacting with the Dead and the Living, Wiley, pp.79-99, 2020, 9781119481966. 10.1002/9781119482062.ch6 . halshs-02458033

\section{HAL Id: halshs-02458033 https://shs.hal.science/halshs-02458033}

Submitted on 10 Feb 2022

HAL is a multi-disciplinary open access archive for the deposit and dissemination of scientific research documents, whether they are published or not. The documents may come from teaching and research institutions in France or abroad, or from public or private research centers.
L'archive ouverte pluridisciplinaire HAL, est destinée au dépôt et à la diffusion de documents scientifiques de niveau recherche, publiés ou non, émanant des établissements d'enseignement et de recherche français ou étrangers, des laboratoires publics ou privés. 
Chapter 6

\section{Unidentified deceased persons: Social life, social death and humanitarian action}

Roberto C. Parra1,2* Élisabeth Anstett2 , Pierre Perich3 and Jane E. Buikstra4

1 Human Rights Office of the High Commissioner (OHCHR), United Nations; and Bioarchaeology and Stable Isotope Research Laboratory, Vanderbilt University, Nashville, Tennessee, USA

2 Centre, National de la Recherche Scientifique (CNRS), Paris, France

3 Forensic Department, Hôpital de la Timone, Aix Marseille University, CNRS, EFS, Marseille, France

4 School of Human Evolution and Social Change, School of Life Sciences Interdisciplinary Graduate faculty, Arizona State University, Tempe Campus, AZ, USA

\subsection{Introduction}

When atrocity and death are inflicted upon a group and people are left in the wake of a humanitarian crisis, the corpses and body parts, their agency, their memories and history assume a special social tension (Dreyfus and Anstett, 2017; Moon, 2012; Buikstra, 2017; Cook, 2015; De Leon, 2015; Anstett and Dreyfus, 2014; Tung, 2014; Fontein, 2010; Hoskins, 2006; Card, 2002, Laqueur, 2002; among others). In the recent history of humanity, extreme violence used against the living and the dead as well as a growing variety of sophisticated ways to destroy bodies, lead to an enourmous production of inert bodies and body parts (Anstett, 2018). All these bloody episodes require new thoughts for humanitarian action to be conducted in an appropriate way. In many ways, social sciences and forensic sciences need to unite to face such humanitarian challenges.

Social sciences have had a decisive influence on legitimizing the body as an object of inquiry, which also highlights its solid cultural role based on its symbolic agency (Crossland, 2009; Bourdieu, 1990, 1985; Turner, 1991; Corbin et al., 2005; Douglas, 2004 [1970], 1979, 2002 [1966]; among others). Therefore, the agency of the corpses and body parts, their history and memories that are associated to, must be taken into consideration, respected and commemorated which contribute to understand and process episodes of death through various forms of cultural expression in worldwide (Robben, 2018; Krmpotich, et al., 2010; Wilson, 2003; Hallam et al., 1999; Metcalf and Huntington, 1991; Hertz, 1960; among others). Such cultural displays of respect and consideration contribute positively to maintain a balance in terms of mental health for the members of a society, directly contributing to the emotional well-being of those people who have lost a loved one (Stroebe et al., 2007).

By contrast, the posthumous dignity of the dead might be threatened by various forms of cruelty, inhuman, or degrading treatment, such as mutilation, dissolution with chemical agents and other mechanisms of destruction that attempt to completely eliminate the identity (whether administrative, or social and cultural) of the deceased. In these events, the social life of the dead loses its coherence, and their loved ones are left submerged in a permanent suffering that negatively impact all survivors. Along the same line, we find that when we do not know or recognize the identity of a deceased person, the corpse or the body parts remain in a forced social anonymity, what Mary Douglas (2002 [1966]) has referred to as a "matter out of place"; this state implies that the body of a deceased person remains liminal, and is considered as an unclassified object removed by the society from all cultural, social and kinship affiliation as long as its identity is not precisely determined. Furthermore, some societies deny 
to an unidentified body its very human condition and therefore right to dignity. In these contexts, forced disappearance as well as reappearance of anonymous corpses becomes a humanitarian tragedy that transgresses fundamental principles such as the right of the relatives to know the fate of their loved ones . Pauline Boss (2017) argued that "Without proof of death, the family are forced to imagine their own ending to their loss. This is immensely challenging and is not required when there is evidence of death" (2017: 522).

In humanitarian forensic work, the process begins with the search, location, and rescue of the body, as well as the application of scientific techniques to reconstruct and preserve their identity. This process has a symbolically restorative effect among those who survived, and it goes along with the undeniable right to respect the dignity of those who have died (Cordner and Tidball-Binz, 2017; Moon, 2017, 2012; Tidball-Binz, 2012; De Baets 2009, 2004). Humanitarian forensic science focuses on this point: to "reunite" the dead body with its personhood in life through identification and, as consequence to restore its kinship ties with its loved ones (Moon, 2017).

This chapter considers a humanitarian approach to mitigate the disruption in continuity of identity that may lead to social death of the unidentified deceased persons. Here we argue that an adjustment in the forensic approach is required, and that this adjustment implies prioritizing the rescue of bodies and their belongings from those places where they remain buried and in anonymity.

\subsection{The social life of dead bodies}

The dead permanently influence the thoughts and behavior of the living (Robben, 2018; Buikstra, 2017; Moon, 2012; Shimada and Fitzsimmons, 2015; Tung, 2014; Fontein and Harries, 2013; De Baets, 2009, 2004; Howarth, 2010; Wilson, 2003; Hallam et al., 1999; Metcalf and Huntington, 1991; Hertz, 1960), therefore maintaining an active social life. Claire Moon (2012) has pointed out that a dead body has a social life playing several special roles as elements of social contact, confluence, and conflict. Based on an Andean case study where approximately 240 individuals were dismembered, Tiffiny Tung (2014:450) notes that "Those mutilated corpses were not just passive symbols of power and physical prowess; they also generated authority for those who killed and butchered them". She argues that dead bodies can structure human interactions, shape social networks, and configure systems of power. A clear example of these connections can be found in Afro-descendent societies of the Pacific coast in Colombia, where there is a particular respect for people who have suffered a violent death. Usually, the perpetrators of these crimes subject their victims to dismemberment while still alive with the intention of provoking a severe hemorrhage, since they believe that ripping the body apart facilitates the release of the spirit through exsanguination $\neg-$ the spirit leaves the body with the blood. In this way, the perpetrator avoids possible persecution by the deceased's soul and also blocks any possibility of a spell that could be practiced by the deceased person's family to find them. The soul, after leaving the body through the hemorrhage, loses its course in the world of the living without any chance of locating its executioner. In order to achieve the perpetrator's goal, the parts of a single body must be buried together in a specific place, still carrying its belongings. These mutilated bodies and their associated possessions not only represent passive symbols of animistic cultural power, but they are also elements that force the perpetrators to bury them respecting their own agency. In the Kasai Culture of the Democratic Republic of Congo, burials are an essential part of life as well, and if the dead 
are not properly buried and accompanied in their new journey, their spirit can haunt the living. As for the opening of graves mass, for the Kasai cultural context would mean to produce living dead whose power would be considered absolute, a kind of invincible zombies.

As Jane Buikstra (2017) notes, dead bodies are never neutral "They demand our attention. They demand action that forces the living to think about what is proper and what is not and act accordingly" (2017:295). In Peru, the story of the death of a child in the highland town of Cidruyo (Junin), exemplifies this influence of the dead on the realm of "appropriateness". The perpetrators of this murder were forced to honor the child's death by placing his belongings inside the burial context, including one flute, two pets a parrot and a pig. In addition, they performed a ritual as sign of commemoration and respect for the deceased child; the perpetrators understood that both the child's body and its associated objects had a special meaning that forced them to think and act with honor in the face of death.

In 1990, One of the authors of this chapter observed that in the Tuamotu Islands (French Polynesia), a dead although properly buried may become uncomfortable and intolerant. When a Tuamoto group do not support the pressure exerted by this dead, it can dig up the corpse in order to incinerate, thus precipitating its full destruction and consequently its ultimate death. For the particular case of the Tuamoto the dead bodies may therefore cast a negative shadow that threatens the thinking of the living and makes it difficult to continue living peacefully, in this case the dead can be completely eliminated. Certain funeral traditions in South, Southeast and East Asia, destroy the dead body as quickly as possible, more often by cremation. In these mortuary as well as commemorative rituals the dead body matters actually far less that the spirit and the memory of the deceased (Tsuji, 2018; Desjarlais, 2018; Wilson, 2002).

In the southwest of Colombia, during the 2015 , several cases have been observed of deceased bodies that were not claimed by their direct relatives. In some cases, the relatives did not want to have notices of their deceased relative because they considered that they have caused considerable harm to society. In other cases, families preferred not to recover a body that was identified as a family member by the forensic team, claiming that they had lost contact with this person. In all these cases families had feelings of fear in front of their own society. However, in one case the combat partners of the deceased requested the International Committee of the Red Cross (ICRC) to mediate with the public authorities to claim the body and belongings, move it to a safe place and give the dead the respective honors in secret. Situations like these can arise, but in most of the cases the families are claiming the body back or at least request to know about the fate of the dead body and its final disposition.

Douglas (1971) uses the example of laughter to illustrate the idea and the importance of the body, in this case the dead body as "matter out of place". Laughter is a physiological function that starts in the face, but that can affect the whole body. However, it is the social situation that determines the extent to which the body can laugh: the fewer restrictions, the freer the body is to laugh out loud; in this way, the dead body expresses itself symbolically and becomes a symbol of the situation. The dead body transmits information about the situation (as the story of the death of a child in the highland town of Cidruyo), so that the more traditional the place, the more formal it will be and the greater the pressures exerted on it. In autochthonous populations of the central Andes and among the indigenous people of 
Amazonian zone, the bodies of the buried unidentified deceased persons can be understood for this communities as a symbolic means highly associated with violence and moral injury. Thousands of human remains are indeed still buried in clandestine graves and in other places where those bodies were thrown such as rivers and lagoons during the Peruvian armed conflict (1980-2000), by perpetrators of the killings. Affecting in this way the cultural landscape and social order of the Andean communities (Robin Acevedo, 2015) as "Matter out the place" in material terms (places of deposit of bodies without respect) as in the symbolic interaction with those anonymous deaths which implies that those Corpses and body parts "have been violated, have suffered indignities" (Rosenblatt, 2010: 948).

The degradation and destruction of the bodies -or their abandonment- constitute a form of violence that directly impacts the mentality of the living (De Leon, 2015; Rosenblatt, 2010). Rosenblatt has argued that "The violence against the bodies in mass graves reaches across the boundaries of life; it is committed first against living human beings and then against their dead bodies" (2010:948). The social landscape imposes indeed itself on the body and constrains it to act in a concrete way, thus, the body becomes a symbol of the situation as a permanent icon of violence both structurally and culturally (Galtung, 1969, 1990).

Gell (1998) and Latour (2005) have theorized about such subjects, where the body and its objects have their own agency and can also influence the behavior of the living (Tung, 2014; Hoskins, 2006). Various other perspectives support the idea of a social life of the dead, including its symbolic influence, its posthumous dignity, and the respect for its agency (De Baets, 2009, 2004; Buikstra, 2017; Moon, 2012, 2017; Tung, 2014, Crandall and Martin, 2014; Fontein and Harries, 2013; Harper, 2010, among others), although others strongly disagree with this perspective (Rosenblatt, 2010). Among these, Rosenblatt (2010) focuses on the distinction between the Universal Declaration of Human Rights and the idea that individuals may maintain these rights after death. He argues that "in the case of the dead, at least, ideas of agency seem 'quite controversial' indeed, too shaky and too shifting a foundation to support the structure of human rights" (Rosenblatt, 2010:934). He further states that "the dead not only do not have human rights; they also do not have inherent dignity" (Rosenblatt, 2010:941). However, the American political scientist does recognize that the processes of location and recovery of the bodies help to restore identity and memory. At the opposite of Rosenblatt view, some domestic law, such as French one for example, recognize the dead body as a "sacred thing" [Labé, 2006] and attribute to the corpse some specific rights such as the right to have its integrity respected. In French law, any arm caused to the integrity of a cadaver is punishable according to the article 225-17 of the Criminal Code. The dead body in this precise -legal and domestic- context therefore do have rights.

Nevertheless, around the world, hundreds of thousands of dead bodies with unknown identities still remain in forced anonymity, whether in cemeteries, clandestine locations, morgues, or forensic laboratories. This situation affects numerous and various social orders, in different countries, since dead body anonymity projects an image of a human being who does not matter to other members of society and who is marginalized, sometimes up to oblivion, until its complete disappearance (due to the decomposition of its organic structure), despite the fact that there are thousands of people who are still searching for their disappeared relatives and waiting for news. As Bryan Turner (1991) has highlighted: 
"The question of the body as a classificatory system has been fundamental to the anthropological vision of Mary Douglas; the main theme of her whole work is the human response to disorder in which may be included risk, uncertainty, and contradiction. The principal response to disorder is systematic classification: the creation of ordered categories which both explain disorder and restore order" (1991:5).

In the context of a forensic humanitarian approach, the main response to disorder would be the classification of the dead body through the definition of its identity -placing the body as "matter inside of place" - to set up the processes of location, recovery, identification, and restoration of identity and care (restitution and burial). Furthermore, Mary Douglas notes that there are two kinds of bodies, the physical body and the social body so that:

"The social body constrains the way the physical body is perceived. The physical experience of the body, always modified by the social categories through which it is known, sustains a particular view of society. There is a continual exchange of meanings between the two kinds of bodily experience so that each reinforces the categories of the other. As a result of this interaction the body itself is a highly restricted medium of expression" (Douglas, 2004 [1970]:72).

As Bourdieu has emphasized "the body is in the social world, but the social world is also in the body" (Bourdieu, 1990:90) and its focus on the important role of the body in the reproduction of culture (Bourdieu, 1985, 1998) which would imply that if we live among or over unidentified bodies, our social life would be in disarray, because by doing so we transgress the socially sanctioned behavior on the treatment of the dead. In this regard, as the anthropologist Claude Lévi Strauss (1955) wrote, "there is probably no society that does not treat its dead with respect. At the borders of the human species, even Neanderthal man buried his dead in summarily arranged tombs" (Lévi-Strauss, 1955:119). Robert Hertz (1960) wrote as well, "The body of the deceased is not regarded like the carcass of some animal: specific care must be given to it and a correct burial; not merely for reason of hygiene but out of moral obligation" (Hertz, 1960: 27). The biological and social properties of the dead body are, then, the starting point for the culture that mediates and translates them into "a system of natural symbols" (Douglas, 2004 [1970]).

We start here with the principle that the image of the body is constructed both socially and culturally: the human body is the image of society if not the entire world, and there is no way of considering the body that does not imply, at the same time, a social dimension (Berger and Luckmann, 1993). In effect, these principles feed our understanding of how the socialization process is also a process of individuation (Bourdieu, 1998) through "objective life paths in the "social space" and generator of subjective conceptions, expectations and tastes - and practices - activities socially codified and reproduced over time, promoting both social structuration and the actors incorporation of adjusted mental, corporal and emotional dispositions" (Abrantes, 2013:392). 
Therefore, the biohistory of the anonymous dead need to be classified with their own identity. TidballBinz (2012) stressed that scientific identification arises from our "shared responsibility for the dead, from which derives the humanitarian need for ensuring their proper recovery, management, analysis and identification, to protect their dignity and to prevent them from becoming missing persons". Additionally, Cook (this volume) has highlighted the importance of returning remains of the deceased to their loved ones, but when this is not possible, at least the bodies should be rescued from the places where they were condemned to disrespect.

As Rocío Magaña (2011) eloquently argues, attending to dead bodies "creates opportunities for the state to emphasize its protective proficiency and authority despite the structural abandonment and weakness that cause these deaths" (Magaña, 2011:170). It is evident that one of the most urgent needs of relatives who are looking for a loved one -in this case, someone who has disappeared and died-is the recovery of the dead body and its confirmed identification, and if this is not possible, at least to know what happened to them, to try to honor their memory and alleviate the suffering of their relatives (CICR, 2013).

Sian Cook (this volume) has used the concepts of "posthumous dignity" (De Baets, 2004), "boundary object" (Star and Griesemer, 1989) and "moral injury" (Maguen and Litz, 2012) to build a theoretical framework referring to the importance of safeguarding the dignity of the deceased. He concludes not only that dignity after death should be considered but underlines also that "the deceased are unable to protect their dignity and it becomes the responsibility of the living to safeguard it. The living can safeguard posthumous dignity by fulfilling the responsibilities of the living" (Cook, this volume). Along the same line of thought, we agree with Claire Moon (2016), who points out that:

"The principles of 'respect' and 'dignity' underpin, shape, and dominate the protocols governing humanitarian treatment of the dead. These principles tell us something about the social importance of the dead and are reflections of widespread social norms older and more pervasive than those of IHL which, in turn, reflects and objectifies those norms. That is, it turns them into the objects of legal administration" (Moon, 2016:58).

We should also reflect on the idea of leaving the bodies in burial sites until finding more information to recover them. Early in this chapter, we argued that the body has a social life and therefore some humanitarian needs that must be considered. Thousands of bodies are still in individual burial sites, mass graves, or other deposit sites waiting for rescue or recovery, decomposing and at risk of disappearing completely. From a humanitarian perspective, should we continue working under a model that implies leaving the body in the same place where it was originally deposited in anonymity until documentation is advanced, or should we rethink the approach?

\subsection{The social death of dead}


As an active social agent, there are several ways in which the dead are kept alive in the cognitive and social realms of the living. However, the dead can also die socially when three components of social life are lost: 1 ) social identity; 2) social connectedness, and 3) losses associated with the disintegration of the body. The loss of social identity is related to the symbolization of an anonymous body, when the body is not clearly identified, while the loss of connectedness is represented by the absence of ritual, commemoration, and memory that hinders the process of dignifying the deceased and their loved ones. We agree with the definition of this "connectedness" between the living and the dead provided by Shimada and Fitzsimmons (2015), when they argue that:

"Death is immutable, perturbs us to varying degrees and triggers a wide variety of emotional, behavioral, organizational, ideological and material responses and consequences at both individual and communal level. Yet, death does not end erase emotional bonds or sense of indebtedness, memory, and other form of interpersonal relationships established in life" (2015:3).

The "connectedness" between dead and living is "forming a cycle that constantly renews itself" (Allen, 2015:316), but when this relationship is broken, this valuable indicator of the "social death" of a person is lost. On the other hand, the category of "losses associated with disintegration of the body" means that our social identity is inevitably connected to, and enacted through, our bodies (Hockey and Draper, 2005; Králová, 2015). In many societies, when the dead body is lost and/or is disintegrated before having been ritually properly treated, the social life of the dead is at threat. The situation can then escalate up to the dead body's social death if the other dimensions have also been transgressed. However, the recomposition or strengthening of their "connectedness" can serve as restorative actions to preserve the social life of the dead, despite the fact that the other dimensions have been affected.

Thus in Buenaventura (Colombia), some relatives of missing and deceased persons who were never able to find the body of their loved ones due to various circumstances have been practicing a form of social and cultural "reconnection" to maintain the social life of the dead and to avoid social death. The group of women maintaining this tradition is named "Mothers for life"; they practice the socialization of their pain through a reparative mechanism that they have called "the ritual of the absent body". As part of this ritual, the memory and cultural identities of the deceased are highlighted, accompanied by chants and praises to the deceased, and their life and actions are remembered and symbolized, conforming a scenario of dignification. In this context, "Mothers for life" have managed to strengthen the memory of their deceased relatives and their identity despite the fact that the body has been disintegrated or lost. Mothers for life "have found resilience using their own culture and their own cosmovision, they have identified the path to finding meaning, adjunct mastery, recontructing identity, normalizing ambivalence and revisioning attachment (Boss, 2017). Bell (2006:542) suggests that "A funeral without a body must, by eulogy or gesture or metonymic association, create a type of body that can be mourned, fondled by grief, and then laid very clearly to rest". Similar experiences have been described for other contexts (Bolt, 2018).

De Baets (2009) has classified the duties of the living towards the deceased into four categories related to: body and property (body, funeral, burial, will), personality (Identity, Image, Speech), general (heritage) and consequential rights (Memory and History) (see Cook, this volume for further 
information). Furthermore, Rosenblatt (2010) proposes that to mitigate violence against bodies, it is necessary to guarantee actions to preserve the protection of three fundamental aspects, identity, location and care (see Figure 6.1). Sian Cook argues that "if it is not possible to undertake the above duties, then moral injury may be inflicted" (Cook, this chapter) as well as legal actions against such aggressions against the body of the deceased (Gaggioli, 2018).

The social death has a crucial meaning for humanitarian action; as Claudia Card (2010) points out "social death can aggravate physical death by making it indecent, removing all respectful and caring ritual, social connections, and social contexts that can make dying bearable and make one's death meaningful" (Card, 2010:262). Certainly, the descriptions offered by Maria Victoria Uribe (1996) in "Matar, rematar y contramatar", helps us analyzes the symbolism of violent death and dismemberment of the bodies. In these criminal cases, killing and inflicting death is not enough; rather, it is necessary to eliminate all traces of the victims existence, including preying against their identity through dismemberment, in addition to causing terror to their family members (Rajs et al., 1998; Holmes, 2017). In accordance with Gaggioli (2018) "Mutilating dead bodies is a horrendous act that is performed out of contempt for the dead and the living, and often to terrorize the enemy through the display of lugubrious 'war trophies' " (2018:187). The mutilation of the bodies is a serious attack against the dignity of the deceased; these are behaviors that have been criminalized and severely sanctioned by international laws in order to protect the dignity of the deceased and their families, as well as to preserve information that entail to elucidate the identity of the victims and circumstances of their death (Gaggioli, 2018).

The social death of the dead bodies can thus in many contexts be understood as a collective moral injury which should be prevented by the authorities and the population itself, regardless of who is the deceased victim. After the loss of identity and the disappearance of dead body itself, memorialization emerges here as a main tool of dignification, which itself is a fundamental component of a humanitarian approach in forensic sciences along with the documentation and recording of "landscapes of dignification" (Parra et al., this volume; Bolaños, 2016). The use of Geographic Information Systems (GIS) technology can in such situations offer an important contribution of the forensic sciences to the restoration of lost components of victim's recognition, such as identity and connectedness.

\subsection{Unidentified dead bodies and deposit sites}

The bodies of the unidentified deceased persons may be deposited in various places such as morgues, cemeteries (regular and irregular), or clandestine deposit sites.

1) Morgues: These are places where bodies are deposited temporarily before and after autopsy, either in conservation chambers or in the open, depending on the logistic capabilities of the forensic services. In general, the risk of body disappearance is minimal, but other problems can arise, including an inadequate management of the corpses or body parts due to various factors (e.g. lack of 
conservation cold rooms, lack of maintenance of conservation cameras, and space limitations, among others, (see Figures $6.2,6.3$ ). In cases of mass disasters, morgues are usually overwhelmed, and their possibilities of storage, registration, and traceability can be dramatically reduced if there are no adequate procedures for such events. When there is no previous preparation, the risk of disappearance of corpses and body parts increases considerably.

2) Regular Cemeteries: After forensic work is conducted in the morgue, corpses and body parts are most often sent to cemeteries to be deposited in common graves or in specific places depending on the logistic capabilities. For example, in Sao Paulo (Brazil), bodies are sent to various cemeteries in the city -mainly Vila Formosa or San Pedro- where they are buried in specific places. In Tegucigalpa (Honduras) bodies are deposited in a humanitarian cemetery especially dedicated to honor the memory of the deceased. Something similar occurs in Colombia where all corpses and body parts are sent to specific cemeteries to be buried individually (see Figure 6.4), even in high-risk areas such as Quibdo, Tumaco and Buenaventura where humanitarian practices have evolved satisfactorily. Peru and Mexico have begun to develop similar practices only in the last few years, thus minimizing the risk of disappearance of the corpses and body parts in regular cemeteries.

When looking in depth to military contexts, Laura Wittman (2011) has highlighted that:

"The ceremonial burial of one anonymous body, gathered from the battlefield and given a proper tomb was a cathartic to mass death and the irretrievable loss of so many bodies and the event had immense cultural and popular appeal. The Unknown Soldier was at once a representation of the body of the nation and of the human body, both felt to be ruptured, perhaps permanently, by the war and by modernity. The Tombs of the Unknown Soldiers was a new memorial invented by the Italians, the French and the British, in the last years of the war and its immediate aftermath, though it is clear that concept of the Unknown Soldiers was widespread in all combatant nations, including the United State and Germany. (Wittman, 2011:3)".

In 1914, during the WWI, in front of the exceptional accumulation of anonymous dead, in both countries, France and Germany, emerged a strong popular demand to recover the bodies of soldiers missing in action, or at least to perform a worthy burial. In France, the right for a soldier to benefit from an individual and identified grave has been thus part of a law passed on December 29, 1915, giving a specific status to those who were "Morts pour la France" ("dead for the Country", see Perich and Pouget, 2019; Pau 2010, 2016).

Nevertheless, all countries in the world do not necessarily follow the best practices regarding burial of corpses and body parts in regular cemeteries and keep on depositing them in common graves or in other inappropriate places (see Figure 6.5), thus hindering their location when they are finally identified. This serious problem was made visible mainly in Colombia after the identification of thousands of bodies that could not be located in regular cemeteries due to previous mismanagement. 
3) Irregular Cemeteries: These cemeteries are not necessarily linked to disrespectful sites and rather preserve the memory of the deceased but are not known by public authorities. They differ from the clandestine sites due to their purpose and symbolic action. Irregular cemeteries indeed do not try to hide or conceal corpses and body parts; they try to preserve the memory of the deceased instead. A clear example is the cemetery in the small town of Bocas de Satinga, along the Pacific Coast of Colombia, where two local people decided to bury dozens of bodies that they rescued from a river. They understood that by recovering corpses and body parts they would preserve the memory of these individuals so that they could be identified with the help of forensic specialists in the future. Other examples of irregular cemeteries are numerous battlefields (such as those related to WWI or WWII, the Vietnam war, the Iran-Iraq war, or the Pacific war between Peru, Chile, and Bolivia, among others) where the bodies are still deposited in the same place where they felt dead, or where their battle companions or even sometimes enemies managed to hastily bury them.

4)

5) Clandestine deposit sites: Among the places included in this category are clandestine burial sites, cremation furnaces, rivers, and other dumping locations (cliffs and abysses, among others). These sites do not necessarily perpetuate memory; on the contrary, their purpose is to facilitate oblivion and disappearance. While decomposition (in rivers, lakes, or oceans), cremation and dissolution (with chemical substances) facilitate the disappearance of physical evidence, clandestine burial sites offer the opportunity to at least physically recover the remains of the people buried there. However, depending on the environmental context of the place of deposit, the risk of disappearance increases over time.

Three of the categories presented above -e.g. morgues, regular cemeteries, and irregular cemeteriespreserve the social life of the deceased. In these places the dead bodies still maintain their agency as human beings, and forensic sciences can be used in order to bring back their identity. Meanwhile, in the case of the clandestine deposits, the risk of erasing the social life of the deceased is extremely high, if it is not acted upon immediately. If no action occurs, the social death of the corpses is imminent, carrying with it the loss of their memory and the respect for their relatives who are still looking for them.

\subsection{Dignifying the life of the dead}

The forensic work behind the identification of corpses and body parts in several different scenarios is well known (Blau, 2016). In cases of massive disaster, corpses and body parts are recovered, transferred to specialized forensic centers where their identification is prioritized, while unidentified corpses and body parts are sent to specific cemeteries. Similarly, in cases of corpses and body parts belonging to migrants that are rescued and recovered from various sites, forensic information is collected and if an identification is not possible the bodies are temporarily deposited in mortuaries or cemeteries (regular or irregular), while waiting for more information about their identity. Meanwhile, when dealing with human remains resulting from political, ethnic, and/or religious violence, the forensic approach changes drastically due to the sensitivity attached to the cases (Fondebrider, 2002). In this scenario, corpses and body parts are usually recovered years after the deathly events and 
scientific documentation is collected prior to the recovery of the human remains, with the exception of those cases where there are imminent threats and where the bodies must be recovered promptly (Fondebrider, 2002).

\subsubsection{Rescue and burial as a Humanitarian mechanism}

It is generally agreed that successful forensic work involving the recovery of evidence contained in clandestine graves requires previous research, what Latin American forensic specialists call preliminary forensic investigation (ALAF, 2015). Without this requirement, graves should not be opened, due to the lack of information about the background and context of death of the people presumedly buried there. While this is a standard that has been used for more than three decades and has brought good results in various scenarios, it is not necessarily applicable with the same rigor in scenarios where dozens of years have passed since the disappearance and death of the victims. Taking this situation into account, should the classic forensic paradigm be generalized for all contexts? Or is a paradigm adjustment necessary to prioritize forensic actions that take into account the dignity of the deceased and the needs of their relatives? Is it necessary to recover corpses and body parts as soon as possible in order to dignify their memory while preserving their bio-history? We argue that in countries like Peru, Colombia, and Guatemala, and as it happens in other regions in the world with similar environments (time since the interment events, and characteristics of the conflicts), a humanitarian rescue of the bodies is of primary importance to avoid total decomposition of their organic structure (the disintegration of the body) and to restore their dignity as human beings. However, it is clear that humanitarian actions of this nature cannot be carried out in all scenarios due to cultural factors, beliefs about the dead, contamination by unexploded ordnance, political contexts or even ongoing hostilities. When conflict ceases, and adequate conditions to location and recovery of the bodies are guaranteed, the first step should be to carry out simultaneously the rescue of bodies and the humanitarian action aiming at forensic documentation of the identities of the possible deceased, as well as the documentation about the contexts of death. Certainly, Moon (2012) has argued that bodies and their belongings are boundary objects :

"They lie at the intersection of different social worlds in which diverse parties - legal, forensic, humanitarian, historical, political, social and familial - are differently invested. Boundary objects link different - sometimes converging, sometimes diverging - interests, allowing groups to form working relationships" (Moon, 2012: 160).

Scientists, society and the authorities as a whole must recognize the liminality of the intermediate facilities of the Unidentified Deceased Persons, special power of ambiguity and unresolved nature of their situation. "The relationship between the significance of remains and their "use" can either safeguard the dignity of the deceased or inflict moral injury" (Cook, this volume). The liminality of the boundary object has a strong social impact that transcends as a moral injury in society and culture. 
In Peru, as well as in several other Latin American countries, thousands of bodies are disappearing from the places where they were buried by their perpetrators, aided by environmental conditions, microorganisms, anthropogenic actions, humidity and particular chemical components in the soil that are forcing a second disappearance of the individuals by degrading all physical evidence of their existence. Certainly, in the case of Peru (Parra et al., this volume), specialists have spent dozens of years developing forensic investigations about who could be buried in a certain site, but when it comes time for recovery the bodies have practically disintegrated or are so damaged that it is not possible to document their bio-history, even at the molecular level.

In Colombia, Mexico, and Peru a model has thus been devised to protect and restore at the same time the dignity of the deceased without losing rigor in the forensic investigation. This model consists in rescuing the bodies and placing them in funerary structures specially built to preserve the dignity of the deceased, while they wait for future forensic analyses. These actions have achieved enormous success as a symbolic mechanism of respect for the deceased and the society as a whole, where the state serves as an agent that cares for its members and restore the dignity of those who have died. The main idea in this model is to rescue the bodies so that no one is left behind, recovering and relocating them in dignified places until their identity can be determined and they can finally be returned to their relatives.

\subsection{Conclusion}

This chapter discusses the importance of the social life of the dead and their profound connection with the social life of the living, as well as the imminent risk of a social death if the bodies of those who have died are not rescued in time. Additionally, we agree with the notion of respect to their posthumous dignity as human beings. Posthumous dignity, agency, and the social life of the dead are theoretical foundations that contribute to our understanding of humanitarian action in forensic sciences beyond a legal perspective. This interpretation should be considered-in addition to the legal framework-from a social and cultural perspective, taking into account worldviews and needs of the relatives. Here lies the difference between the application of forensic sciences from a humanitarian approach and the use of forensic sciences in the context of Human Rights. We argue that the recovery of bodies should facilitate the restoration of the deceased's posthumous dignity; this implies that the body should be rescued as soon as possible from the place where it was deposited in a disrespectful way and then placed in a dignified site where to wait until its identity can be determined. Otherwise the moral injury may be inflicted allowing the social death of the dead. Finally, prevention and mitigation of the social death of the corpses and body parts is a forensic humanitarian action beyond legal foundations

\section{References}

Abrantes, P. (2013) Opening the black box of socialization: Emotions, practices and (biographical) identities. International Journal of Sociology and Anthropology 5(9), 391-401.

Ahern, L. (2001) Language and agency. Annual Review of Anthropology, 30, 109-137. 
Allen, C. (2015) The Sadness of Jar: Separation and Rectification in Andean Understandings of Death (eds. I. Shimada and J.L. Fitzsimmons). University of Arizona Press, Tucson. pp. 304-328.

Anstett, E. (2018) What Is a Mass Grave? Toward an Anthropology of Human Remains Treatment in Contemporary Context of Mass Violence. In: A Companion to the Anthropology of Death (ed. A.C.G.M. Robben). John Wiley and Sons, Inc. pp. 177-188.

Anstett, É. and Dreyfus, JM (ed) (2014) Destruction and human remains: Disposal and concealment in genocide and mass violence. Manchester University Press

Bell, C. (2006) Embodiment. In: Theorizing Rituals: Issues, Topics, Approaches, Concepts (eds. J. Kreinath, J. Snoek, and M. Stausberg). Brill, Leiden, The Netherlands, pp. 533-544.

Berger, P.L. and Luckmann, T. (1967) The Social Construction of Reality. London: Allen Lane.

Biohistory: Anthropological Perspective (eds. C. Stojanowski and W. Duncan). Cambridge Studies in Biological and Evolutionary Anthropology. Cambridge University Press, Cambridge, pp. 288-314.

Blau, S. (2016) Missing persons investigations and identification: Issues of scale, infrastructure, and political will. In: Handbook of Missing Persons (eds. S.J. Morewitz and C. Sturdy Colls). Springer International Publishing, Switzerland, pp. 191-206

Blumer, H. (1962) Society as symbolic interaction. In: Human Behavior and Social Process: An Interactionist Approach (ed. A.M. Rose). Houghton-Mifflin Co, Boston, 78-88.

Bolaños, A. (2016) The landscape of the disappeared in Peru. Trialog, 118-119(3-4), 18-24.

Bolt, S. (2018) In the absence Companion to the Anthropology of Death (ed. A.C.G.M. Robben). John Wiley and Sons, Inc., pp, 371381.

Boss, P. (2017). Families of the missing: Psychosocial effects and therapeutic approaches International Review of the Red Cross (2017), 99 (2), 519-534.

Bourdieu, P. (1985) The Social Space and the Genesis of Groups. Theory and Society, 14(6), 723-744.

Bourdieu, P. (1990) Lecture on the lecture. In: Other Words: Essays Towards a Reflexive Sociology (ed. P. Bourdieu). Polity Press, Cambridge.

Bourdieu, P. (1998) Practical Reason: On the Theory of Action. Polity Press, Cambridge.

Buikstra, J. (2017) Ethical issues in Biohistory: No easy answers! In: Studies in Forensic

Card, C. (2002) The Atrocity Paradigm: A Theory of Evil. Oxford University Press, Oxford.

Card, C. (2010) Confronting Evils: Terrorism, Torture, Genocide. Cambridge University Press. Cambridge.

Cook, S. (2015) The Return of Remains: How can Dignity be Better Safeguarded? Thesis, Uppsala University, Uppsala.

Corbin, A., Courtine, JJ and Vgarello, G (eds), Histoire du corps. Paris, Le Seuil, 3 volumes.

Cordner, S., and Tidball-Binz, M. (2017) Humanitarian forensic action: Its origins and future. Forensic Sci Int, 279, 65-71. 
Crandall, John J. and Martin, DL. (2014) The bioarchaeology of postmortem agency: Integrating archaeological theory with human skeletal remains. Cambridge Archaeological Journal, 2014, vol. 24, no 3, p. 429-435.

Crossland, Z. (2009) Of clues and signs: the dead body and its evidential traces. American anthropologist, 2009, vol. 111, no 1, p. 69-80.

De Baets, A. (2004) A declaration of the responsibilities of present generations towards past generations. History and Theory, 43(4), 130-164.

De Baets, A. (2009) Responsible History. Berghahn Books, New York.

De Leon, J. (2015) The Land of Open Graves: Living and Dying on the Migrant Trail. University of California Press.

Desjarlais, R. (2018) Learning how to die. In: A Companion to the Anthropology of Death (ed. A.C.G.M. Robben). John Wiley and Sons, Inc., pp 251-264.

Douglas, M. (1979) "Do Dogs Laugh". A Cross Cultural Approach to Body Symbolism. Journal of Psychosomatic research, 15(4) 387-390

Douglas, M. 2002 (1966) Purity and Danger: An Analysis of Concepts of Pollution and Taboo. Routledge, London and New York.

Douglas, M. 2004 (1970) Natural Symbols. Explorations in Cosmology. Taylor and Francis Group.

Dreyfus, JM. and Anstett É, 2017. Human remains in society. Curation and exhibition in the aftermath of genocide and mass violence. Manchester, MUP, 254pp.

Duncan WN and Stojanowski CM. (2017) Theoretical Facets of Biohistorical Research. In C. Stojanowski \& W. Duncan (Eds.), Studies in Forensic Biohistory: Anthropogical Perspective (Cambridge Studies in Biological and Evolutionary Anthropology, pp. 315-327). Cambridge: Cambridge University Press.

Fondebrider, L. (2002) Reflections on the scientific documentation of Human Rights violations. International Review of the Red Cross, 84(848), 885-890.

Fontein, J and Harries, J. (eds). (2013) The Vitality and Efficacy of Human Substances. Special issue of Critical African studies 5(3). 115-126, DOI: 10.1080/21681392.2013.847660

Fontein, J and Harries, J. (2013) The vitality and efficacy of human substances. Critical African Studies, vol. 5, no 3, p. 115-126.

Fontein, J. (2010) Between tortured bodies and resurfacing bones: the politics of the dead in Zimbabwe. Journal of Material Culture, vol. 15, no 4, p. 423-448.

Gaggioli, G. (2018) International Humanitarian Law: The legal framework for humanitarian forensic action. Forensic Science International, 282, 184-194.

Galtung, J. (1969) Violence, peace, and peace research. Journal of Peace Research, 6(3), 167-191.

Galtung, J. (1990) Cultural violence. Journal of Peace Research, 27(3), 291-305.

Gell, A. (1998) Art and Agency: An Anthropological Theory. Clarendon Press, Oxford and New York. 
Hallam, E., Hockey, J., and Howarth, G. (1999) Beyond the Body. Death and Social Identity. CRC Press, Taylor and Francis Group.

Harper, S. (2010) The social agency of dead bodies. Mortality, 2010, vol. 15, no 4, p. 308-322.

Hertz, R. (1960) A Contribution to the Study of the Collective Representation of Death and Right Hand. Cohen and West, London.

Hockey, J., and Draper J (2005) Beyond the womb and the tomb: Identity, disembodiment and the life course. Body and Society, 11, 41-58.

Holmes, D. (2017) Psychology and dismemberment. In: Criminal Dismemberment: Forensic and Investigative Analysis (eds. S. Black, G. Rutty, S. Hainsworth, and G. Thomson). CRC Press.

Hoskins, J. (2006) Agency, biography and objects. In: Handbook of Material Culture (eds. C. Tilley, W. Keane, S. Kuchler, M. Rowlands, and P. Spyer). Sage, London, pp. 74-85.

Howarth, E. (2010) Dismantling the boundaries between life and death. Mortality, 5(2), 127-128.

International Committee of the Red Cross (2013) Accompanying the Families of Missing Persons: A Practical Handbook. ICRC.

Králová, J. (2015) What is social death? Contemp Soc Sci, 10, 235-248.

Krmpotichk, C., Fontein, J., and Harries, J. (2010) "The substance of bones: the emotive materiality and affective presence of human remains". Journal of Material Culture, vol. 15, no 4, p. 371-384.

Laqueur, T. (2002) The dead body and human rights. The Body, 2002, p. 75-93.

Latour, B. (2005) Reassembling the Social: An Introduction to Actor-Network-Theory. Oxford University Press. Oxford.

Lévi-Strauss, C. (1988 [1956]) Tristes trópicos. Ediciones Paidós Ibérica, S.A.

Magaña, R. (2011) Dead bodies: The deadly display of Mexican border politics. In: A Companion to the Anthropology of Embodiment (ed. F. Mascia-Lees). Blackwell Publishing. 157-151

Maguen, S., and Litz, B. (2012) Moral injury in veterans of war. PTSD Research Quarterly, 23(1), 1-6.

Metcalft, P. and Huntington, R. (1991) Celebrations of Death: The Anthropology of Mortuary Ritual (2nd edn.). Cambridge University Press, Cambridge.

Moon, C. (2012) Interpreters of the dead: Forensic knowledge, human remains and the politics of the past. Social and Legal Studies, 22(2), 149-169.

Moon, C. (2016) Human rights, human remains: Forensic humanitarianism and the human rights of the dead. International Social Science Journal, 65(215-216), 49-63.

Moon, C. (2017) The biohistory of atrocity and the social life of human remains. In: Studies in Forensic Biohistory: Anthropological Perspective (eds. C. Stojanowski and W. Duncan). Cambridge Studies in Biological and Evolutionary Anthropology, Cambridge University Press, Cambridge. pp. 267-287.

Pau Béatrix, La violation des sépultures militaires, 1919-1920 RHA n² 259, 2010

Pau Béatrix, Le Ballet des morts. État, armée, familles: s'occuper des corps de la Grande Guerre, Vuibert, 2016 
Perich P., Pouget B. (2019). Le médecin-légiste dans le conflit et le post-conflit, De l'intervention additionnelle au recours systématique, Revue historique des armées (RHA) $n^{\circ} 294$, Service historique de la Défense, Château de Vincennes, 94306 Vincennes, France.

Rajs, J., Lundstrom, M., Broberg, M., et al. (1998) Criminal mutilation of the human body in Swedena thirty-year medico-legal and forensic psychiatric study. J Forensic Sci, 43(3), 563-580.

Robben, A.C.G.M. (ed.) (2018) A Companion to the Anthropology of Death. John Wiley and Sons, Inc.

Robin Azevedo, V. (2015) D'os, d'habits et de cendres: Corps exhumés et reconfiguration des dispositifs rituels et symboliques dans le Pérou post-conflit. Revue européenne des sciences sociales, 53-2(2), 75-98.

Rosenblatt, A. (2010) International forensic investigations and the human rights of the dead. Human Rights Quarterly, 32(4), 922-951.

Shimada, I., and Fitzsimmons, L.J. (2015) Introduction. In: Living with the Dead in the Andes (eds. I. Shimada and J.L. Fitzsimmons). University of Arizona Press, Tucson, pp. 3-50

Star, S.L., and Griesemer, J.R. (1989) Institutional ecology, 'translations' and boundary objects: Amateurs and professionals in Berkeley's Museum of Vertebrate Zoology 1907-1939. Social Studies of Science, 19(3), 387-420.

Stroebe, M., Hansson, R., Stroebe, W., and Schut, H. (eds.) (2007) Handbook of Bereavement Research: Consequences, Coping and Care. American Psychological Association. Washington, DC.

Tidball-Binz, M. (2012) For whom the bell tolls: The development of humanitarian forensic action. Keynote speech, Victorian Institute of Forensic Medicine, Monash University, Melbourne, Australia. 7 June.

Tsuji, Y. (2018) Evolving mortuary ritualsisepij contemporary Japan. In: A Companion to the Anthropology of Death (ed. A.C.G.M. Robben). John Wiley and Sons, Inc. pp. 17-30.

Tung, T. (2014) Agency, 'Til death do as part? Inquiring about the agency of dead bodies from the ancient Andes. Cambridge Archaelogical Journal, 24(3), 437-452.

Turner, B. (1991) Recent development in the theory of the body. In: The Body: Social process and Cultural Theory (eds. M. Feathertone, M. Hepworth, and B. Turner). Sage, London. pp. 157-169.

Uribe, M.V. (1996) Matar, rematar y contramatar. Cinep, Bogotá.

Wilson, S. (2003) The Living and the Dead: Social Dimension of Death in South Asian Religions. State University of New York.

Wittman, L. (2011) The Tomb of the Unknown Soldier, Modern Mourning, and the Reinvention of the Mystical Body. University of Toronto Press. 


\section{Figures captions}

Figure 6.1 Prevention and mitigation of social death as a forensic humanitarian action. Conceptual framework adapted from De Baets (2009), Rosenblatt (2010) and Králová 2015.

Figure 6.2 Unidentified bodies deposited in cold rooms of a morgue.

Figure 6.3 Saturation of unidentified bodies in spaces to store bodies in a morgue

Figure 6.4 Humanitarian funerary structure to store unidentified bodies

Figure 6.5 Human remains deposited in a regular cemetery

\section{Acknowledgment}

The authors wish to thank Jana Králová and Claire Moon for her valuable comments on an earlier draft of this chapter. 